\title{
Reduction in interval cancer rates following the introduction of two-view mammography in the UK breast screening programme
}

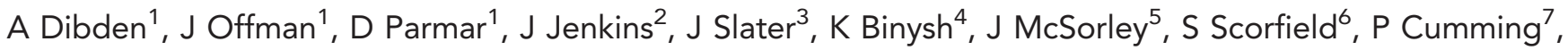
X-H Liao ${ }^{8}$, M Ryan ${ }^{9}$, D Harker ${ }^{10}$, G Stevens ${ }^{11}$, N Rogers ${ }^{12}$, R Blanks ${ }^{13}$, S Sellars ${ }^{14}$, J Patnick ${ }^{14}$ and S W Duffy ${ }^{*}, 1$

${ }^{1}$ Policy Research Unit in Cancer Awareness, Screening and Early Diagnosis, Queen Mary, University of London, Wolfson Institute of Preventive Medicine, Charterhouse Square, London EC1M 6BQ, UK; ${ }^{2}$ East Midlands Quality Assurance Reference Centre (QARC), Nottingham University Hospital City Campus, Hucknall Road, Nottingham NG5 1PB, UK; ${ }^{3}$ East of England QARC, 2nd Floor, Compass House, Chivers Way, Vision Park, Histon, Cambridge CB24 9AD, UK; ${ }^{4}$ London QARC, 1st Floor, 51/53 Bartholomew Close, London EC1A 7BE, UK; ${ }^{5}$ Northern Ireland QARC, 18 Ormeau Avenue, Belfast BT2 8HS, UK; ${ }^{6}$ North East, Yorkshire and the Humber QARC, Waterfront 4, Goldcrest Way, Newburn Riverside Newcastle upon Tyne, NE15 8NY, UK; ${ }^{7}$ North West QARC, Hollinwood Business Centre, Albert Street, Oldham OL8 3QL, UK; ${ }^{8}$ South Central QARC, 4150 Chancellor Court, Oxford Business Park South, Oxford OX4 2GX, UK; ${ }^{9}$ South East Coast QARC, 77a High Street, Battle, East Sussex TN33 OAG, UK; ${ }^{10}$ South West QARC, 1st Floor, Grosvenor House, 149 Whiteladies Road, Clifton, Bristol BS8 2RA, UK; ${ }^{11}$ Public Health Wales, 18 Cathedral Road, Cardiff CF11 9LJ, UK; ${ }^{12}$ West Midlands Breast Screening QARC, Public Health Building, University of Birmingham, Birmingham B15 2TT, UK; ${ }^{13}$ Cancer Epidemiology Unit, University of Oxford, Richard Doll Building, Roosevelt Drive, Oxford OX3 7LF, UK and ${ }^{14}$ NHS Cancer Screening Programmes, Fulwood House, Old Fulwood Road, Sheffield S10 3TH, UK
\end{abstract}

Background: The introduction of two-view mammography at incident (subsequent) screens in the National Health Service Breast Screening Programme (NHSBSP) has led to an increased number of cancers detected at screen. However, the effect of two-view mammography on interval cancer rates has yet to be assessed.

Methods: Routine screening and interval cancer data were collated from all screening programmes in the United Kingdom for women aged 50-64, screened between 1 April 2003 and 31 March 2005. Interval cancer rates were compared based on whether two-view mammography was in use at the last routine screen.

Results: The reduction in interval cancers following screening using two-view mammography compared with one view was 0.68 per 1000 women screened. Overall, this suggests the introduction of two-view mammography at incident screen was accompanied by a 15-20\% reduction in interval cancer rates in the NHSBSP.

Conclusion: The introduction of two-view mammography at incident screens is associated with a reduction in incidence of interval cancers. This is consistent with previous publications on a contemporaneous increase in screen-detected cancers. The results provide further evidence of the benefit of the use of two-view mammography at incident screens.

Mammography using two views (craniocaudal in addition to the standard mediolateral oblique view) became standard practice in the National Health Service Breast Screening Programme
(NHSBSP) at prevalent (first) screens in 1995, with single-view mammography used at incident (second and subsequent) screens. This followed the UKCCCR randomised controlled trial comparing

*Correspondence: Professor SW Duffy; E-mail: s.w.duffy@qmul.ac.uk

Received 7 August 2013; revised 13 November 2013; accepted 17 November 2013; published online 24 December 2013 (c) 2014 Cancer Research UK. All rights reserved 0007 - 0920/14 
the cancer detection rate achieved when using one vs two-view mammography during routine breast screening. Results showed a $24 \%$ increase in cancer detection with two-view mammography (Wald et al, 1995).

Further research was undertaken, including a number of observational studies, which found that programmes using twoview mammography saw an $8.9 \%$ increase in sensitivity (true cancer detection) for invasive cancer detection compared with those using a single view only (Blanks et al, 1998). This led to the decision that two-view mammography would be undertaken at all incident screens as well as prevalent screens. The aim was for all units in the United Kingdom to be using two-view mammography at all screening rounds by December 2003 (Patnick, 2004) but in practice, only $81 \%$ of units ( 74 out of 91 units) had achieved this target. All screening units in England, Wales and Northern Ireland were using two-view mammography at incident screens by 1 December 2004. The programme in Scotland adopted two-view mammography in 2008 (NHS Scotland, 2008). It should be noted that screening units in Northern Ireland used two-view mammography at both prevalent and incident screens when the breast screening programme was introduced in 1989.

Assessment of the impact of the introduction of two-view vs one-view mammography has been carried out in relation to screendetected cancer and recall rates. Blanks et al (2005) found the overall rate of invasive and in situ cancers detected at screen increased by 0.65 per 1000 women screened following the introduction of two-view mammography with recall rates falling by 0.27 per 1000 women screened .To date, there has been no assessment on the impact of the introduction of two views on interval cancer rates in the UK screening programme; therefore, this is what we explore in this study. We focus on the UK breast screening programme as the screening regimes in other countries differ to that in the United Kingdom. In particular, the interval between routine screening episodes varies; in the United Kingdom, it is 36 months whereas many other European countries with national screening programmes have a screening interval of 24 months (Giordano et al, 2012) and thus, it would be difficult to compare changes in interval cancer rates. Also, we were particularly keen to assess whether the recent policy change in the United Kingdom, in relation to the use of two-view mammography at incident screens, has been of equal benefit for interval cancer rates as it has been for screen-detected cancer rates.

Interval cancers are those that occur symptomatically in the interval between routine screening episodes. These can be cancers which were missed by screening, cancers which became screen detectable after the screen and then became symptomatic, and cancers not detectable by mammography (Warren and Duffy, 2000). Interval cancer rates provide a good indicator of the performance of a screening programme; therefore, assessment of the change in interval cancer rates following the introduction of two-view mammography is of interest.

\section{MATERIALS AND METHODS}

The NHSBSP currently invites women aged 50-70 to attend breast screening every 3 years. Screening years, and subsequent reporting, run from 1st April to 31st March the following year. Expansion of the age range to $47-73$ is being introduced, in a randomised fashion, to enable full evaluation of the benefit of expanding the screening age. We collated annual screening and interval cancer data for all UK breast screening units for the screening years 2003/ 04 and 2004/05 from the NHS Information Centre and the Breast Screening Quality Assurance Reference Centres (QARCs), respectively. Accurate assessment of interval cancer rates is often hampered by the poor availability of necessary data. The NHSBSP, however, has a rigorous system in place to ensure all screening and interval cancer data are correctly identified and recorded. Cancer registries are responsible for the identification of all breast cancers diagnosed in their catchment area, including interval cancers. Data are then collated on a regional level by QARCs, who assign a screening history to each case of breast cancer diagnosed in women eligible for screening, from which the cancer status can be identified. The QARCs assess these data against numerous quality indictors to ensure ascertainment is good before being made available for analysis (NHS Breast Screening Programme, 2006). This is a process that can take some time, particularly in the identification of interval cancers, as they can occur up to 3 years after a women's previous screen. The most recent data available for analysis, during which both one- and two-view mammography was in use, were for screening years 2003/04 and 2004/05. Also, over $50 \%$ of screening units introduced two-view mammography at incident screen in screening year 2002/03; therefore, any analysis undertaken prior to 2003/04 would not have had a sufficient number of units which had fully implemented two-view mammography at incident screen for a complete screening year.

Only interval cancers occurring within 36 months of a woman's last negative screen were included, in line with the NHSBSP screening guidelines for analysing interval cancers.

Only women aged 50-64 at last screen were included in the analysis as not all units had extended the screening age to 70 years during the study period. Data relating to routine screening were available for all 91 screening units in the United Kingdom for both screening years and included details of the number of women screened and the number of cancers detected. Interval cancer data were available for all screening units for both screening years, apart from the six screening units in Scotland, who were only able to provide data for screening year 2003/04.

As two-view mammography for incident screens was in the process of being introduced during our study period, we categorised units as follows:

- Full two view: the screening unit carried out two-view mammography for the whole screening year of interest;

- Partial two view: the screening unit introduced two-view mammography at some stage during the screening year of interest;

- One view only: the screening unit carried out one-view mammography only during the screening year of interest.

Interval cancers were defined as cancers diagnosed following a normal screening result during the interval beginning with the closure of the previous NHS screening episode and ending when the next screening episode was due to commence (NHS Breast Screening Programme, 2006). The dates to be used for the screening episodes were the date when the last screening mammogram was taken and the date of the next routine screening appointment, where this was less than 36 months. If the next appointment was more than 36 months after the last mammogram, only interval cancers up to 36 months after the latter were included. The way in which round length is defined means that the achievement of the national standard is not affected by women choosing to alter their screening appointment - a woman's round length is determined by the date of first offered appointment (DOFOA) (NHS Breast Screening Programme, 2008). A screening episode is closed when the screening outcome is known or 180 days after DOFOA in the case of non-attenders.

The aim of this analysis was to assess the effect of the introduction of two-view mammography on interval cancer rates in the NHSBSP. Confidentiality regulations restricted the availability of individual data, so we were unable to conduct analyses on a per-patient level. We calculated the rates of interval cancers per 1000 women screened by the two-view mammography status of 
the unit as defined above. We assessed the rates of invasive interval cancers only and of all interval cancers; and for each screening year separately and the two screening years combined. Poisson regression was used to assess whether the rates varied by twoview status. Analyses were performed using STATA Version 11.2 (College Station, TX, USA; Stata Corp, 2009).

As interval length, that is, the length of time elapsing between two consecutive screens, varied between units, we repeated the analysis restricting it to interval cancers that occurred within 24 months following a negative screen.

Where regional boundaries changed during the period under scrutiny, the configuration of regions and responsibilities for screening units was taken to be that which existed in screening year 2009/10, when the interval cancer data were first compiled. Five pairs of screening units merged prior to this but as the introduction of two-view mammography occurred in the same screening year for each merged pair, the change in configuration will not have had an impact on the results of this study. One new screening unit was opened in the South West region during screening year 2004/05. This unit was excluded. Therefore, data from 91 screening units in the United Kingdom were included in the study.

\section{RESULTS}

A total of 1400613 women were screened across 91 screening units in 2003/04, giving an average of 15391 women screened per unit (range 3835-45632). A total of 9957 cancers were detected as a result of screening (unit range 22-309) giving an average rate of 7.11 cancers detected per 1000 women screened. As data for Scotland were unavailable for screening year 2004/05, data on 1278989 women screened across 85 units (unit range 3979-33 521) were available for analysis. This resulted in 9192 cancers being detected (unit range 33-251) leading to an average rate of 7.19 cancers detected per 1000 women screened. A total of 4518 interval cancers were identified following screens in 2003/04 and 3915 following screens in 2004/05, of which 4212 (93.2\%) and 3665 (93.6\%) respectively, were invasive cancers.

Table 1 shows the number of units by two-view mammography status for each screening year. In 2003/04, 70.3\% units had fully implemented two-view mammography; this had risen to $87.9 \%$ in $2004 / 05$.

The interval cancer rate decreased upon the implementation of two-view mammography in screening year 2003/04 (Table 2). There was a $17 \%$ reduction (RR: 0.83 (95\% CI $0.77-0.90$, $P<0.001)$ ) in interval cancers occurring following screening using two-view mammography compared with single-view mammography. A slightly smaller but significant reduction was also seen when comparing interval cancer rates in units which introduced two views at some stage during the screening year compared with those units that used one-view mammography only (RR: 0.86 (95\% CI $0.78-0.95, P=0.004)$ ).

\begin{tabular}{|c|c|c|}
\hline Mammography Status & $\begin{array}{l}1 \text { April } 2003 \text { to } \\
31 \text { March } 2004\end{array}$ & $\begin{array}{l}1 \text { April } 2004 \text { to } \\
31 \text { March } 2005\end{array}$ \\
\hline One view only & 11 & $6^{a}$ \\
\hline Partial two view & 16 & 5 \\
\hline Full two view & 64 & 80 \\
\hline
\end{tabular}

By 2004/05, all screening units had introduced two-view mammography either before the start of, or at some stage during, the screening year. There was a significant reduction in interval cancers of $13 \%$ (RR: 0.87 (95\% CI $0.76-0.99, P=0.035)$ ) in units which used two-view mammography throughout the screening year compared with units who introduced it part way through.

Combining the data from both screening years produced similar results to those seen when analysing 2003/04 data only. There was an $18 \%$ reduction (RR: $0.82(95 \%$ CI $0.76-0.88, P<0.001)$ ) in interval cancers occurring following a screen using two-view mammography for the whole screening period compared with units which used single view only.

We repeated the analysis to assess the effect of the introduction of two-view mammography on invasive interval cancers only (Table 3). There was no significant difference in interval cancer rates following screening in year 2003/04 between units which had introduced two-view mammography part way through the year compared with units using one-view mammography only. There was, however, a $10 \%$ reduction (RR: 0.90 (95\% CI $0.83-0.98$, $P=0.017)$ ) of invasive interval cancers occurring in units using two-view mammography for the whole screening year compared with one-view mammography only.

When analysing women screened in $2004 / 05$, there was a $14 \%$ reduction (RR: $0.86(95 \% \mathrm{CI} 0.75-0.98, P=0.027)$ ) in the number of women who developed invasive interval cancers following screening at units that had fully implemented two-view mammography compared with units that introduced it part way through the year. This is similar to the reduction seen for all interval cancers.

For both screening years combined, there was no significant difference in interval cancer rates between units that used one-view mammography only and units that introduced two-view mammography part way through the screening year. However, there was a significant $12 \%$ reduction (RR: $0.88(95 \%$ CI $0.81-0.96, P=0.003)$ ) in invasive interval cancer rates for women screened at units using two-view mammography compared with those using one-view mammography only.

Repeating the analysis restricting the diagnosis of interval cancer to within 24 months following a negative routine screen produced similar results to those shown in Tables 2 and 3. However,

\begin{tabular}{|c|c|c|c|c|}
\hline $\begin{array}{l}\text { Mammography } \\
\text { in use }\end{array}$ & $\begin{array}{l}\text { Number } \\
\text { of } \\
\text { women } \\
\text { screened }\end{array}$ & $\begin{array}{l}\text { Number } \\
\text { of } \\
\text { interval } \\
\text { cancers }\end{array}$ & $\begin{array}{c}\text { Rate per } \\
1000 \\
\text { women } \\
\text { screened }\end{array}$ & $\begin{array}{l}\text { Rate ratio } \\
(95 \% \mathrm{Cl})\end{array}$ \\
\hline \multicolumn{5}{|c|}{1 April 2003 to 31 March 2004} \\
\hline $\begin{array}{l}\text { One view only } \\
\text { Partial two view } \\
\text { Full two view }\end{array}$ & $\begin{array}{l}195224 \\
249865 \\
955524\end{array}$ & $\begin{array}{r}732 \\
808 \\
2978\end{array}$ & $\begin{array}{l}3.75 \\
3.23 \\
3.12\end{array}$ & $\begin{array}{c}\text { Baseline } \\
0.86(0.78-0.95) \\
0.83(0.77-0.90)\end{array}$ \\
\hline \multicolumn{5}{|c|}{1 April 2004 to 31 March 2005} \\
\hline $\begin{array}{l}\text { One view only } \\
\text { Partial two view } \\
\text { Full two view }\end{array}$ & $\begin{array}{c}N / A^{a} \\
68379 \\
1210610\end{array}$ & $\begin{array}{r}N / A^{a} \\
239 \\
3676\end{array}$ & $\begin{array}{l}N / A^{a} \\
3.5 \\
3.04\end{array}$ & $\begin{array}{c}\mathrm{N} / \mathrm{A}^{\mathrm{a}} \\
\text { Baseline } \\
0.87(0.76-0.99)\end{array}$ \\
\hline \multicolumn{5}{|c|}{1 April 2003 to 31 March 2005} \\
\hline $\begin{array}{l}\text { One view only } \\
\text { Partial two view } \\
\text { Full two view }\end{array}$ & $\begin{array}{r}195224 \\
318244 \\
2166134\end{array}$ & $\begin{array}{r}732 \\
1047 \\
6654\end{array}$ & $\begin{array}{l}3.75 \\
3.29 \\
3.07\end{array}$ & $\begin{array}{c}\text { Baseline } \\
0.88(0.80-0.96) \\
0.82(0.76-0.88)\end{array}$ \\
\hline \multicolumn{5}{|c|}{$\begin{array}{l}\text { Abbreviation: } \mathrm{Cl}=\text { confidence interval. } \\
\text { a Only six units in Scotland used one view only in 2004/05, and for these units data were not } \\
\text { available. }\end{array}$} \\
\hline
\end{tabular}




\begin{tabular}{|c|c|c|c|c|}
\hline $\begin{array}{l}\text { Mammography } \\
\text { in use }\end{array}$ & $\begin{array}{c}\text { Number } \\
\text { of } \\
\text { women } \\
\text { screened }\end{array}$ & $\begin{array}{l}\text { Number } \\
\text { of } \\
\text { interval } \\
\text { cancers }\end{array}$ & $\begin{array}{c}\text { Rate per } \\
1000 \\
\text { women } \\
\text { screened }\end{array}$ & $\begin{array}{l}\text { Rate ratio } \\
(95 \% \mathrm{Cl})\end{array}$ \\
\hline \multicolumn{5}{|c|}{1 April 2003 to 31 March 2004} \\
\hline $\begin{array}{l}\text { One view only } \\
\text { Partial two view } \\
\text { Full two view }\end{array}$ & $\begin{array}{l}195224 \\
249865 \\
955524\end{array}$ & $\begin{array}{r}638 \\
761 \\
2813\end{array}$ & $\begin{array}{l}3.27 \\
3.05 \\
2.94\end{array}$ & $\begin{array}{c}\text { Baseline } \\
0.93(0.84-1.04) \\
0.90(0.83-0.98)\end{array}$ \\
\hline \multicolumn{5}{|c|}{1 April 2004 to 31 March 2005} \\
\hline $\begin{array}{l}\text { One view only } \\
\text { Partial two view } \\
\text { Full two view }\end{array}$ & $\begin{array}{r}N / A^{a} \\
68379 \\
1210610\end{array}$ & $\begin{array}{r}\mathrm{N} / \mathrm{A}^{\mathrm{a}} \\
226 \\
3439\end{array}$ & $\begin{array}{l}\mathrm{N} / \mathrm{A}^{\mathrm{a}} \\
3.31 \\
2.84\end{array}$ & $\begin{array}{c}\text { N/A } \\
\text { Baseline } \\
0.86(0.75-0.98)\end{array}$ \\
\hline \multicolumn{5}{|c|}{1 April 2003 to 31 March 2005} \\
\hline $\begin{array}{l}\text { One view only } \\
\text { Partial two view } \\
\text { Full two view }\end{array}$ & $\begin{array}{r}195224 \\
318244 \\
2166134\end{array}$ & $\begin{array}{r}638 \\
987 \\
6252\end{array}$ & $\begin{array}{l}3.27 \\
3.10 \\
2.89\end{array}$ & $\begin{array}{c}\text { Baseline } \\
0.95(0.86-1.05) \\
0.88(0.81-0.96)\end{array}$ \\
\hline \multicolumn{5}{|c|}{$\begin{array}{l}\text { Abbreviations: } \mathrm{Cl}=\text { confidence interval. } \\
\text { aOnly six units in Scotland used one view only in 2004/05, and for these units data were not } \\
\text { available. }\end{array}$} \\
\hline
\end{tabular}

$\sim 44 \%$ of interval cancers were diagnosed in the third year following a negative routine screen in both screening years 2003/04 and 2004/05 (1958/4 518 and $1728 / 3915$, respectively) and thus the reduction in sample size led to wider confidence intervals. Results are shown in Tables 4 and 5.

\section{DISCUSSION}

The introduction of two-view mammography has led to a reduction in interval cancers occurring following a negative routine screen in comparison with one-view mammography. This is consistent with a corresponding rise in the number of cancers detected at screening (Blanks et al, 2005). The reduction in all interval cancer rates associated with two-view mammography was 0.68 per 1000 screened (Table 2, both screening years combined), very close to the 0.65 per 1000 increase from 5.87 to 6.52 in screendetection rates in the Study Group of Blanks and colleagues (Blanks et al, 2005). This indicates that the increase in screendetection rates with two-view mammography is not likely to be attributable to overdiagnosis. Overdiagnosis is the detection, by screening, of cancers that would never have come to clinical attention had screening not taken place (Duffy, 2005). If the decrease in interval cancer rates was smaller than the increase in screen-detected cancers, then the excess in screen-detected cancers following the introduction of two-view mammography may be as a result of overdiagnosis. However, given that the increase in screendetected cancers is consistent with the decrease in interval cancers, the number of additional screen-detected cancers using two-view mammography, which are attributable to overdiagnosis, is likely to be minimal. There is always room for argument about overdiagnosis, as the phenomenon cannot be observed at an individual level. However, the results here suggest that at least there is no cause for alarm in this respect over the change to two-view mammography. Further observation of both screen-detected and interval cancer rates in the future will be useful in terms of likely overdiagnosis due to other innovations such as digital mammography.

A study in France found a larger proportional effect of changing from single- to two-view mammography on two-year interval cancer rates, finding a reduction of more than $30 \%$
Table 4. Interval cancer rates by screening year for cancers diagnosed within 24 months of last routine screen

\begin{tabular}{|l|c|c|c|c|}
\hline Mammography & $\begin{array}{c}\text { Number } \\
\text { of }\end{array}$ & $\begin{array}{c}\text { Number } \\
\text { of }\end{array}$ & $\begin{array}{c}\text { Rate per } \\
1000\end{array}$ & Rate ratio \\
in use & women & interval & $\begin{array}{c}\text { women } \\
\text { screened }\end{array}$ & $(95 \% \mathrm{Cl})$ \\
\hline & screened & cancers & screen
\end{tabular}

\section{April 2003 to 31 March 2004}

\begin{tabular}{|l|r|r|r|c|}
\hline One view only & 195224 & 399 & 2.04 & Baseline \\
Partial two view & 249865 & 465 & 1.86 & $0.91(0.80-1.04)$ \\
Full two view & 955524 & 1696 & 1.78 & $0.87(0.78-0.97)$ \\
\hline
\end{tabular}

\section{April 2004 to 31 March 2005}

\begin{tabular}{|l|r|r|c|c|}
\hline One view only & N/A & N/A & N/A & N/A \\
Partial two view & 68379 & 127 & 1.89 & Baseline \\
Full two view & 1210610 & 2060 & 1.7 & $0.92(0.77-1.10)$ \\
\hline
\end{tabular}

\section{April 2003 to 31 March 2005}

\begin{tabular}{|l|r|r|r|c|}
\hline One view only & 195224 & 399 & 2.04 & Baseline \\
Partial two view & 318244 & 592 & 1.86 & $0.91(0.80-1.03)$ \\
Full two view & 2166134 & 3756 & 1.73 & $0.85(0.77-0.94)$ \\
\hline
\end{tabular}

Abbreviation: $\mathrm{Cl}=$ confidence interval.

a Only six units in Scotland used one view only in 2004/05, and for these units data were not available.

Table 5. Invasive interval cancer rates by screening year for cancers diagnosed within 24 months of last routine screen

\begin{tabular}{|c|c|c|c|c|}
\hline $\begin{array}{l}\text { Mammography } \\
\text { in use }\end{array}$ & $\begin{array}{l}\text { Number } \\
\text { of } \\
\text { women } \\
\text { screened }\end{array}$ & $\begin{array}{l}\text { Number } \\
\text { of } \\
\text { interval } \\
\text { cancers }\end{array}$ & $\begin{array}{c}\text { Rate per } \\
1000 \\
\text { women } \\
\text { screened }\end{array}$ & $\begin{array}{l}\text { Rate ratio } \\
(95 \% \mathrm{Cl})\end{array}$ \\
\hline \multicolumn{5}{|c|}{1 April 2003 to 31 March 2004} \\
\hline $\begin{array}{l}\text { One view only } \\
\text { Partial two view } \\
\text { Full two view }\end{array}$ & $\begin{array}{l}195224 \\
249865 \\
955524\end{array}$ & $\begin{array}{r}355 \\
435 \\
1589\end{array}$ & $\begin{array}{l}1.82 \\
1.74 \\
1.66\end{array}$ & $\begin{array}{c}\text { Baseline } \\
0.96(0.83-1.10) \\
0.91(0.82-1.03)\end{array}$ \\
\hline
\end{tabular}

1 April 2004 to 31 March 2005

\begin{tabular}{|l|r|r|r|c|}
\hline One view only & N/A & N/A & N/A & N/A \\
Partial two view & 68379 & 120 & 1.76 & Baseline \\
Full two view & 1210610 & 1914 & 1.58 & $0.90(0.75-1.08)$ \\
\hline
\end{tabular}

\section{April 2003 to 31 March 2005}

\begin{tabular}{|l|r|r|r|c|}
\hline One view only & 195224 & 355 & 1.82 & Baseline \\
Partial two view & 318244 & 555 & 1.74 & $0.96(0.84-1.10)$ \\
Full two view & 2166134 & 3503 & 1.62 & $0.89(0.80-1.00)$ \\
\hline
\end{tabular}

Abbreviation: $\mathrm{Cl}=$ confidence interval.

a Only six units in Scotland used one view only in 2004/05, and for these units data were not available.

(Seigneurin et al, 2009). However, this study compared universal two-view with universal single view rather than a change for incident screens only, as in our case.

Interval cancers tend to have poorer stage and poorer prognosis as one would expect (Biesheuvel et al, 2011; Nagtegaal et al, 2011; Domingo et al, 2013). Interval cancer rates are in the order of 2-3 per 1000 screened in the UK programme (Bennett et al, 2011). This is somewhat less than $50 \%$ of tumours diagnosed in women attending the programme, but still a non-negligible number. Results from other countries with more frequent screening are consistent with this (Ciatto et al, 2011). Clearly, reduction in 
interval cancer incidence is a suitable target for screening programmes.

The benefit seen following the introduction of two-view mammography was larger when analysing all interval cancers than when restricting to invasive interval cancers only (Tables 2 and 3). This was not simply a feature of greater statistical power with larger numbers, which would lead to smaller standard errors (s.e.) and thus more precise estimates of rates. The absolute and relative reductions in interval cancer rates were also larger when non-invasive cancers are included. This is consistent with the observation that compared with contemporaneous changes in a reference group not using two-view mammography, the proportional increase in detection of in situ tumours with two-view mammography was greater than for invasive (Blanks et al, 2005).

This study uses data on interval cancers from almost all units in the United Kingdom over a 2-year period and thus benefits from large number of women screened and subsequent interval cancers recorded. Also, as the breast screening programme operates on a national level and has a rigorous call/recall system in place, we can be confident that the interval cancer rates calculated accurately reflect the true rates occurring in the population eligible for screening. Many other countries do not have similarly organised population-based screening programmes in place, thus making it difficult to clearly distinguish interval cancers from those detected at screening or in non-attenders.

Assessment of potential confounding factors, such as age at screening, was not possible due to confidentiality restrictions meaning we were unable to obtain data at an individual patient level. Comparison of interval cancer rates by unit may therefore have introduced potential confounders at a geographical level, such as variation in underlying incidence or the recording of interval cancers, or the possibility that units which were quicker to change to twoview mammography are more effective in identifying interval cancers a priori than those still using one view. However, the NHSBSP has a robust quality assurance system in place to ensure that all cancers that occur in women eligible for screening are identified and classified appropriately as well as having strict screening guidelines in place to ensure that all women receive the same high quality level of care when attending screening. Incidence does vary geographically within the United Kingdom, but it is uniformly high. In any case, as interval cancers following subsequent years of screening become available, it will be possible to track interval cancer rates over time by individual screening unit, and assess whether changes in rates are consistent with the time of the move to two-view mammography. By considering changes within rather than between units, geographical/ unit level confounders can be controlled for.

In conclusion, this study found that the introduction of twoview mammography at incident screens was accompanied by a $15-20 \%$ reduction in interval cancer rates in the NHSBSP. This, therefore, supports the decision at national level to change to twoview mammography at incident screens. In Europe, there are a number of programmes which still use single-view mammography at incident screens (Giordano et al, 2012). These results will have relevance for those programmes.

\section{ACKNOWLEDGEMENTS}

We thank the staff at the screening units and QARCs whose hard work provided the data for this paper. SWD, AD and DP contributed to this work as part of the programme of the Policy Research Unit in Cancer Awareness, Screening and Early Diagnosis. The Policy Research Unit in Cancer Awareness, Screening and Early Diagnosis receives funding for a research programme from the Department of Health Policy Research Programme. It is a collaboration between researchers from seven institutions (Queen Mary University of London, UCL, King's College London, London School of Hygiene and Tropical Medicine, Hull York Medical School, Durham University and Peninsula Medical School).

\section{CONFLICT OF INTEREST}

The authors declare no conflict of interest.

\section{REFERENCES}

Bennett RL, Sellars SJ, Moss SM (2011) Interval cancers in the NHS breast cancer screening programme in England, Wales and Northern Ireland. Br J Cancer 104(4): 571-577.

Biesheuvel C, Czene K, Orgeas CC, Hall P (2011) The role of mammography screening attendance and detection mode in predicting breast cancer survival-is there added prognostic value? Cancer Epidemiol 35(6): $545-550$.

Blanks RG, Bennett RL, Patnick J, Cush S, Davison C, Moss SM (2005) The effect of changing from one to two views at incident (subsequent) screens in the NHS breast screening programme in England: impact on cancer detection and recall rates. Clin Radiol 60(6): 674-680.

Blanks RG, Given-Wilson RM, Moss SM (1998) Efficiency of cancer detection during routine repeat (incident) mammographic screening: two $v s$ one view mammography. J Med Screen 5(3): 141-145.

Ciatto S, Bernardi D, Caumo F (2011) Evidence of interval cancer proportional incidence and review from mammography screening programs in Italy. Tumori 97(4): 419-422.

Domingo L, Blanch J, Servitja S, Corominas JM, Murta-Nascimento C, Rueda A, Redondo M, Castells X, Sala M (2013) Aggressiveness features and outcomes of true interval cancers: comparison between screendetected and symptom-detected cancers. Eur J Cancer Prev 22(1): 21-28.

Duffy SW (2005) Some current issues in breast cancer screening. J Med Screen 12(3): 128-133.

Giordano L, von Karsa L, Tomatis M, Majek O, de Wolf C, Lancucki L, Hofvind S, Nyström L, Segnan N, Ponti A (2012) Mammographic screening programmes in Europe: organization, coverage and participation. J Med Screen 19(suppl 1): 72-82.

Nagtegaal ID, Allgood PC, Duffy SW, Kearins O, Sullivan EO, Tappenden N, Wallis M, Lawrence G (2011) Prognosis and pathology of screen-detected carcinomas: how different are they? Cancer 117(7): 1360-1368.

NHS Breast Screening Programme (2006) Audit of Breast Cancers in Women Aged 50 to 74. NHS Screening Programmes: Sheffield.

NHS Breast Screening Programme (2008) Achieving and Maintaining the 36 Month Round Length. NHS Screening Programmes: Sheffield.

NHS Scotland (2008) Better Cancer Care, An Action Plan. The Scottish Government: Edinburgh.

Patnick J (2004) NHS breast screening: the progression from one to two views. J Med Screen 11(2): 55-56.

Seigneurin A, Exbrayat C, Labarere J, Colonna M (2009) Comparison of interval breast cancer rates for two-versus single-view screening mammography: a population-based study. Breast 18(5): 284-288.

Stata Corp (2009) Stata. Stata Corporation: College Station, TX, USA.

Wald NJ, Murphy P, Major P, Parkes C, Townsend J, Frost C (1995) UKCCCR multicentre randomised controlled trial of one and two view mammography in breast cancer screening. BMJ 311(7014): 1189-1193.

Warren R, Duffy S (2000) Interval cancers as an indicator of performance in breast screening. Breast Cancer 7(1): 9-18.

This work is published under the standard license to publish agreement. After 12 months the work will become freely available and the license terms will switch to a Creative Commons AttributionNonCommercial-Share Alike 3.0 Unported License. 